Miri Yemini, Heela Goren \& Claire Maxwell (2018) Global Citizenship Education in the Era Of Mobility, Conflict and Globalisation, British Journal of Educational Studies, 66:4, 423-432.

\title{
Global citizenship education in the era of mobility, conflict and globalisation
}

Miri Yemini, Heela Goren and Claire Maxwell

\section{Abstract}

This special issue (SI) highlights how the transnational flow of people in a 'global age' shapes the needs and aspirations of learners, how citizenship education can engage with this, while taking account of differences across groups and contexts. In this editorial introduction, we introduce a thematic analysis of GCE scholarship to date and consider the contributions of British-based research to this rapidly growing field. We then use this thematic analysis as a framework for examining the unique contribution each paper in this SI makes to the current scholarly landscape and highlighting the specific sub-fields each paper aligns and connects with.

\section{Editorial Introduction}

The seemingly unerring processes of globalisation within education have significantly unsettled understandings of, and teaching practices around the notion of citizenship. Increasingly, studies are depicting a shift within classrooms worldwide from a focus on the construction of a unitary national identity within civics education, to attempts to introduce cosmopolitan ideas (Bromley, 2009) as central to understandings of students' belonging and future imaginaries (Beck, 2006). In particular, while schools were formerly entrusted with the responsibility of promoting local and patriotic values in students, increasingly institutions are adopting a cosmopolitan narrative linked to global citizenship education (GCE). GCE seeks to prepare students to take part in the 'global competition' for future education and employment destinations, participate in 'global problem solving', and, broadly, be better equipped to face the challenges globally connected contemporary societies must engage with (Dill, 2013; Goren \& Yemini, 2017a;b;2018; Reilly \& Niens, 2014; Vidovich, 2004; Yemini, 2018; Yemini \& Furstenburg, 2018).

This changing context of citizenship education is happening partially because of, and running simultaneously alongside, this era of intensive transnational migration - comprised both of chosen and strategic mobility by the most highly resourced groups to forced movement by those fleeing violence and poverty. Thus, classrooms have become more heterogenic and multinational. Within such spaces, the teaching and learning of 'global citizenship' is afforded both opportunities and challenges. This special issue therefore concentrates on the nexus between mobility, identity, and global citizenship education, in an effort to highlight how the transnational flow of people in a 'global age' shapes the needs and aspirations of learners both from (im)migrant and local backgrounds and considers how practitioners and scholars should be re-thinking and re-framing the concept of citizenship and the way it is taught.

The British Journal of Educational Studies has published a number of articles on the theme of this special issue and broader implications of globalisation on discourses of citizenship and identity over the last twenty years (Crick, 2007; Davies, Evans, \& Reid, 2005; Lawy \& Biesta, 2006; Ross, 2007; Oxley \& Morris, 2013). Given this, and the commitment of the Journal to highlight how scholarship is relevant to the UK context, we first introduce a brief thematic analysis of GCE scholarship to date and consider the contributions British-based research has made here. This analysis also enables us to then situate the SI contributions more precisely within the broader 
literature. Furthermore, we consider how each of the published paper should be related to the most comprehensive typology of GCE developed to date, that by Oxley and Morris (2013), also published by the BJES. We conclude by raising some critical questions and contexts that require further study.

Introducing the main strands of research and mapping UK scholarship on the topic

Our thematic analysis is based on a larger, comprehensive network visualization project (for a detailed methodology see Yemini, Tibbitts \& Goren, forthcoming). For this special issue, we concentrate on the UK GCE scholarship, where the analysis reveals four main themes that represent discrete strands of research: skills and pedagogies; cosmopolitanism; education for sustainable development and finally, multiculturalism and internationalisation. In the following section, each theme will be described briefly and illustrated using examples from UK scholarship.

\section{Skills and Pedagogies}

The first theme encompasses topics related to practical skills and pedagogies that are often linked together in the GCE scholarship. The relationship found here supports many claims already made in the literature about the blurred lines between GCE and $21^{\text {st }}$ century skills, which are particularly evident in utilitarian or, as per Oxley and Morris' framework (2013), economic approaches to GCE. The skills associated with GCE include media, information and critical literacy, critical thinking and more. The pedagogies aimed at promoting these skills include experiential and transformative learning. This theme also includes the International Baccalaureate (IB), language education, and English as a second or foreign language. The prevalent association of GCE with a broad set of skills suggests that it is presented in the scholarship in practical rather than idealistic terms.

In the UK-based scholarship, there is an emphasis on concrete skills and pedagogies evident mostly in literature concerning primary and secondary education (Hayden, 2013; Marshall, 2011). Some pedagogies associated with GCE in the UK literature include environmental pedagogies and experiential learning, most commonly discussed in the Welsh and Scottish context (Bennell, 2015), multicultural education and $21^{\text {st }}$ century skills, often mentioned in relation to England (O'Connor \& Faas, 2012), and inclusion, a key concern for GCE in Northern Ireland (Reilly \& Niens, 2014). The IB is also discussed in UK scholarship as one way in which schools aspire to prepare students for global society, although its adoption in England, in particular, is situated within a broader tension pertaining to debates concerning critiques of the traditional Alevel accreditation system and the presentation of the IB as an alternative (Hayden, 2013). Nonetheless, the development and adoption of more internationally-minded programmes within the UK indicates a paradigm shift in the understanding of the scope and purposes of contemporary education.

\section{Cosmopolitanism}

The second theme identified through the analysis concerns cosmopolitanism and globalisation as its key terms, alongside some broad terms such as 'world', multiculturalism and political philosophy. The appearance of these terms together is intuitive, as global citizenship and cosmopolitanism are often used synonymously and globalisation and multiculturalism are often presented as phenomena that drive GCE policy. This theme also includes social inequality, 
neoliberalism, and nationalism, suggesting that in the GCE literature, neoliberalism is considered another factor which drives GCE, as well a point of criticism, as is indicated by its connection to inequality. Indeed, several studies have centered on the negative implications GCE could have for promotion of equality, that are often overlooked for the sake of neoliberal ideals such as competitiveness in the global workforce (Friedman, 2018).

Friedman (2018) suggests that the radical stratification of British HE, itself an indicator of neoliberal processes, leads to the production of vastly different global citizens, who are encouraged to engage with the world in different ways and to different extents. Only some universities, he argues, provide students with the skills and dispositions associated with cosmopolitan capital and neoliberal ideals of succeeding in the global workforce, while others simply introduce GCE as a marketisation tool and provide minimal and abstract engagement with globally oriented contents. In a study of curricular contents, and the views of educators and academics in the Philippines and the UK, Camicia and Franklin (2011) reveal a deep-seeded curricular struggle between neoliberal and democratic discourses and intents that effects education, where neoliberal goals such as preparing students for a global work-force often obscure the promotion of active citizenship and other knowledge associated with democratic forms of GCE.

\section{Education for sustainable development}

The third theme encompasses works that focus on the following topics: sustainable development, education for sustainable development, environmental education, sustainable development goals, UNESCO, natural environment, sustainability, and outdoor education. This theme points to a very distinct strand in the UK-based GCE scholarship devoting itself to these topics in a way that does not necessarily engage with other forms of GCE in any meaningful manner and is somewhat disconnected from the concrete skills, dispositions, and structures found across the other themes. UNESCO has recently announced GCE as part of its 2020 SDGs, binding the concepts of sustainable development [SD] and GCE together in a more coherent way by introducing GCE as a tool or pedagogy for the promotion of SD. Yet, in many ways they were already commonly referred to in tandem in the literature long before this (Regueiro, García, DePalma, \& Matos, 2017). However, the distinctiveness of this theme suggests that these topics are not evenly dispersed throughout the literature and are more likely to appear as stand-alone engagements.

Peace education, another key goal embedded within UNESCO's SDGs, also falls under this theme, and is often presented as another desired outcome or form of GC (see O'Connor, 2012; Reilly \& Niens, 2014).

In research that engages with UK primary and secondary education and policy around GCE and sustainable development or peace education, it was evident that the different country contexts that make up the UK also shape the scholarly landscape. Articles concerning Northern Ireland present GCE as a form of peace education and advocate for the need for a shared identity in a divided nation while questioning the feasibility of this concept (Reilly \& Niens, 2014). In Wales, the explicit connection of GCE to education for sustainable development [ESD] in official policy documents has given rise to a more environmentally conscious GCE (Bamber et al., 2016; Marshall, 2009). In England, GC-related policy has been framed in terms of promoting social cohesion in a time of increased diversity, not in terms of looking outwardly - neither in terms of the environment nor with reference to the global work force (Bamber et al., 2016). Finally, in Scotland there is an outward focus which concerns negotiating and integrating European and 
Miri Yemini, Heela Goren \& Claire Maxwell (2018) Global Citizenship Education in the Era Of Mobility, Conflict and Globalisation, British Journal of Educational Studies, 66:4, 423-432.

national elements of identity and belonging in a way that is underpinned by economic considerations (Mannion, Biesta , Priestley, \& Ross, 2011; Marshall, 2009).

\section{Multiculturalism and internationalisation}

The final theme we introduce here illustrates the common association of GCE with multicultural learning, which is thought to increase as result of globalisation. This theme also includes work related to internationalisation of higher education, owing in large part to the perception of GCE as a concrete manifestation and form of internationalisation. Student exchange and international education are also often mentioned in tandem with these terms, indicating their association in the GCE literature with cultural exposure, the development of intercultural capabilities, and global citizenship in general.

Looking more closely at the UK scholarship, research about the attitudes of British students towards international students in $\mathrm{HE}$ institutions consistently shows disengagement and indifference (Peacock \& Harrison, 2009). These findings suggest that although the policies that bring in international students are often framed in terms of cultural enrichment, in practice there is not much evidence that this benefit is in fact being realized and the true commitment of the institutions to these goals is questioned (Schartner \& Cho, 2017). This ambivalence could be related to the potential clash between global citizenship and 'Britishness', which may be perceived as superior to GC or more useful in the UK context (Marshall, 2009; Osler, 2011). Such an arguably hollowed-out form of GCE exclusively aimed at enabling specific HE institutions to market themselves as internationalised contributes to the understanding of higher education in the UK as being strongly shaped today by neo-liberal marketisation (Friedman, 2018). The graduates of so-called internationalized universities that boast GCE as part of their official agendas are also considered more poised to compete in the global work-force, but based on our analysis, such discursive constructions are actually related to how the institution is perceived and not necessarily to any particular skills or capabilities that graduates are expected to have (Moraes, 2014; Schartner \& Cho, 2017).

\section{Mapping the Special issue contributions}

This Special Issue contributes substantially to the body of empirical studies reviewed above, but critically, papers in this SI create and strengthen links within and between the four themes outlined. It is also critical to consider how this Special Issue engages with the most comprehensive typology of GCE to date, which was developed by Oxley and Morris (2013) and published in the BJES ${ }^{1}$. Bamber tackles the growing policy and practice commitment in England to teach Fundamental British Values. He does this by critically reviewing how a GCE module is delivered to and engaged with in a teacher education programme. Bamber's analysis challenges the dichotomy between the advocacy and cosmopolitan approaches to GCE, by illustrating future teachers' (non)/compliance with this form of provision and their agency in choosing the aspects they feel should be emphasised. Bamber convincingly argues that GCE must be viewed through a nuanced, context-specific lens if teachers are expected to engage with it, embody it and actively implement

\footnotetext{
${ }^{1}$ Oxley and Morris categorize conceptions of global citizenship as either cosmopolitan or advocacy approaches. While cosmopolitan conceptions refer to more traditional aspects such as identification, global consciousness, and understanding of global relations, advocacy-based approaches concentrate on global problem-solving and action.
} 
Miri Yemini, Heela Goren \& Claire Maxwell (2018) Global Citizenship Education in the Era Of Mobility, Conflict and Globalisation, British Journal of Educational Studies, 66:4, 423-432.

it. In doing so, he engages directly with one of the biggest dilemmas in the field of GCE - the tension between local values, culture and nationalism and the global identities that students and teachers might hold simultaneously. Thus, this contribution largely makes links between the pedagogies (first theme) and the internationalisation of schools (the fourth theme).

The second and third contributions in this SI are comparative works, each of which provides a comprehensive, thorough analysis that highlights similarities and differences in conceptions and manifestations of GCE in each of the contexts studied. Dvir, Shields and Yemini's work considers the key messages around GCE constructed by school websites in four locations (Netherlands, Chicago, United Arab Emirates and Hong Kong) who provide the International Baccalaureate (IB). Through their analysis, Dvir, Shields and Yemini identify three distinct interpretations of GCE emerging from the schools' websites. Two of these are found in other IB scholarship (a focus on quality, and moral values). However, the third one, which they call 'neoliberal GCE' has not featured in the IB literature to date, and was prevalent across all four locations studied. This form of GCE corresponds with Oxley and Morris's cosmopolitan approach and specifically embodies the economic form of global citizenship which falls under this approach. This form of GCE focuses on power relations, forms of capital, the work force, and international development. The paper calls for more research on the macro and meso factors which define a schools' environment as these will specifically shape the various variants of GCE that are envisioned and delivered by schools. This paper manages to link three themes - skills and pedagogies (first theme), the notion of neoliberalism (second theme) and schools' images and procedures (forth theme).

In the second comparative paper featured in this Special Issue, Patterson examines GCE at a national policy level in South Korea and Scotland. The analysis focuses specifically on how increasing levels of migration are being engaged with by policy. Patterson's analysis suggests that GCE policy is directly and indirectly marginalising new migrants in both education systems by emphasising nationalistic foci. The paper concludes by suggesting how curricula developers and teachers could more generatively draw on the heterogenic nature of their classrooms and become more inclusive. Patterson's study therefore makes links between a focus on skills and pedagogies (first theme) and multiculturalism and internationalisation (forth theme). This work portrays the less common form of cultural global citizenship as per Oxley and Morris's typology, which emphasizes symbols and cultural structures that divide or unite members of different societies and considers the globalisation of different cultural forms. This form of GCE falls under the cosmopolitan approach, as it is aimed at facilitating social cohesion within these nations undergoing demographic changes through incoming migration.

The final three papers included in this special issue each contrate on a unique national setting, allowing for a more intricate analysis of each context. First, Howard's work focuses on an elite school in Ghana which is promoting GCE as a means to achieve a pan-African identity. Through examining the perceptions of students and staff, he reveals the tension between a stated focus on Africa and becoming leaders for and in Africa, and the need to emmigrate, at least temporarily, to the West in order to attain the necessary higher academic credentials and experiences for this endeavour. Howard also highlights the ways socio-economic and national differences shape perceptions of GCE among students (and staff), despite the school's refusal to acknowledge them. Howard therefore creates a link between the skills and pedagogies used by the school (first theme) and the broader consequences and contexts where such skills might be developed (second theme). 
This work also demonstrates a hybrid of both types of GCE outlined by Oxley and Morris being taught at the elite school, encompassing economic rationales and cultural capital associated with cosmopolitan GCE, and, to a lesser extent, social and critical forms associated with the advocacy approach.

Pak and Lee, in their paper on the implementation of GCE in South Korea, explore the disparities between the formal national curricular policies of GCE (including Education for Sustainable Development [ESD]) versus the actual implementation of the GCE (third theme), in a country where GCE is fully integrated into the school curricula and actively promoted by the state as part of the larger internationalisation strategy (forth theme). This paper, once again, reveals a fluidity or mixture of advocacy and cosmopolitan approaches to GCE, with ESD falling under Oxley and Morris's advocacy-based category of environmental GCE. Yet it's de facto implementation relates more closely to political global citizenship, which focuses on the changing relations between states and individuals or other polities and economic GCE, both of which fall under the cosmopolitan approach. Finally, Kadiwal focuses on the Pakistani education system, where GCE has to be negotiated through religious, tribal, gendered and socio-economical lenses. This contribution enriches the Special Issue by introducing a focus on how identity of individuals is critical in shaping and negotiating the ways various forms of GCE are engaged with and taken up by students from more marginalised communities. This study moves between an examination of the meanings of GCE in the specific context of Pakistani society (second theme) to a detailed discussion of the interplay between citizenship and identity in a conflict-ridden society (forth theme). The kaleidoscopic view of factors that inform GCE introduced by Kadiwal integrates advocacy and cosmopolitan based forms of GCE, calling for policy-makers to adopt moral, humanistic approaches to GCE and allow students to rise above religious and cultural differences within the conflict-ridden context. This points to an inward focus that is first and foremost aimed at meeting the needs of marginalised young people in a conflict-ridden society more so than the prevalent approaches in the other Special Issue papers that concentrate on preparing students to thrive in global society.

Thus, alongside the specific empirical contributions which shed light on various geographical contexts, this Special Issue moves the field of GCE research forward in several ways; by further problematizing one-size-fits-all approaches to GCE and highlighting a wide array of contextual factors that shape its manifestations and goals. Most critically, the SI specifically seeks to link the various themes of GCE scholarship, as part of our commitment to beginning the process of forging a more comprehensive and fluid integration of GCE and its related elements into a more coherent field of study. This will ultimately enable the field to move forward conceptually, as scholars use this review of 'the state of the art' to position their work, and ensure they are making the necessary connections across the various concepts and theoretical influences found in work to date. 
Miri Yemini, Heela Goren \& Claire Maxwell (2018) Global Citizenship Education in the Era Of Mobility, Conflict and Globalisation, British Journal of Educational Studies, 66:4, 423-432.

\section{Acknowledgments}

We thank Dr. Efrat Blumenfeld-Lieberthal and Mr. Nimrod Serok for their generous assistance in the network visualization analysis and algorithm development that informed our thematic review. Prof. Andrew Peterson has also been instrumental in facilitating the reviews for the contributions in this issue, and closely supporting the process throughout.

\section{References}

Andreotti, V. (2006). Soft versus critical global citizenship education. Development Education, Policy and Practice 3 (1), 83-98.

Bamber, P., Lewin, D., \& White, M. (2018). (Dis-) Locating the transformative dimension of global citizenship education. Journal of Curriculum Studies, 50(2), 204-230.

Beck, U. (2006). Cosmopolitan vision. Cambridge: Polity Press.

Bennell, S. J. (2015). Education for sustainable development and global citizenship: Leadership, collaboration, and networking in primary schools. International Journal of Development Education and Global Learning, 7(1), 5-32.

Bromley, P. (2009). Cosmopolitanism in civic education: Exploring cross-national trends, 1970-2008. Current Issues in Comparative Education, 12, 33-44.

Camicia, S. P., \& Franklin, B. M. (2011). What type of global community and citizenship? Tangled discourses of neoliberalism and critical democracy in curriculum and its reform. Globalisation, Societies and Education, 9(3-4), 311-322.

Crick, B. (2007). Citizenship: The political and the democratic. British Journal of Educational Studies, 55(3), 235-248.

Davies, I., Evans, M., \& Reid, A. (2005). Globalising citizenship education? A critique of 'global education' and 'citizenship education'. British Journal of Educational Studies, 53(1), 66-89.

Dill, J. S. (2013). The longings and limits of global citizenship education: The moral pedagogy of schooling in a cosmopolitan age. New York, NY: Routledge.

Friedman, J. Z. (2018). The global citizenship agenda and the generation of cosmopolitan capital in British higher education. British Journal of Sociology of Education, 39(4), 436-450.

Goren, H., \& Yemini, M. (2017a). Global citizenship education redefined-A systematic review of empirical studies on global citizenship education. International Journal of Educational Research, 82, 170-183.

Goren, H., \& Yemini, M. (2017b). The global citizenship education gap: Teacher perceptions of the relationship between global citizenship education and students' socio-economic status. Teaching and Teacher Education, 67, 9-22.

Goren, H., \& Yemini, M. (2018). Obstacles and opportunities for global citizenship education under intractable conflict: The case of Israel. Compare: A Journal of Comparative and International Education, 48(3), 397-413.

Harrison, N., \& Peacock, N. (2009). Cultural distance, mindfulness and passive xenophobia: Using Integrated Threat Theory to explore home higher education students' perspectives on 'internationalisation at home'. British Educational Research Journal, 36(6), 877-902.

Hayden, M. (2013). A review of curriculum in the UK: Internationalising in a changing context. Curriculum Journal, 24(1), 8-26. 
Miri Yemini, Heela Goren \& Claire Maxwell (2018) Global Citizenship Education in the Era Of Mobility, Conflict and Globalisation, British Journal of Educational Studies, 66:4, 423-432.

Kumar, R., Novak, J., \& Tomkins, A. (2010). Structure and evolution of online social networks. In P. S. Yu, J. Han, \& C. Faloutsos (Eds.), Link mining: Models, algorithms, and applications (pp. 337357). New York, NY: Springer.

Lawy, R., \& Biesta, G. (2006). Citizenship-as-practice: The educational implications of an inclusive and relational understanding of citizenship. British Journal of Educational Studies, 54(1), 34-50.

Mannion, G., Biesta, G., Priestley, M., \& Ross, H. (2011). The global dimension in education and education for global citizenship: Genealogy and critique. Globalisation, Societies and Education, 9(3-4), 443-456.

Marin, A., \& Wellman, B. (2011). Social network analysis: An introduction. In P. J. Carrington and J. Scott (Eds.), The Sage handbook of social network analysis (pp.11-25). London, UK: Sage.

Marshall, H. (2009). Educating the European citizen in the global age: engaging with the post-national and identifying a research agenda. Journal of Curriculum Studies, 41(2), 247-267.

Marshall, H. 2011. Education for global citizenship: Reflecting upon the instrumentalist agendas at play. In Schooling internationally: Globalisation, internationalisation and the future for international schools, ed. R. Bates, 182-99. London: Routledge.

Moraes, S. E. (2014). Global citizenship as a floating signifier: Lessons from UK universities. International Journal of Development Education and Global Learning, 6(2), 27-42.

Oxley, L., \& Morris, P. (2013). Global citizenship: A typology for distinguishing its multiple conceptions. British Journal of Educational Studies, 61(3), 301-325.

O’Connor, U. (2012). Schools together: Enhancing the citizenship curriculum through a non-formal education programme. Journal of Peace Education, 9(1), 31-48.

O'Connor, L., \& Faas, D. (2012). The impact of migration on national identity in a globalized world: a comparison of civic education curricula in England, France and Ireland. Irish Educational Studies, 31(1), 51-66.

Osler, A. (2011). Teacher interpretations of citizenship education: National identity, cosmopolitan ideals, and political realities. Journal of Curriculum Studies, 43(1), 1-24.

Regueiro, P. D., García, R. M. M., DePalma, R., \& Matos, S. L. (2017). A place for development education in the current Spanish and English curricula: Finding possibilities for practice. International Journal of Development Education and Global Learning, 9(2), 97-114.

Reilly, J., \& Niens, U. (2014). Global citizenship as education for peacebuilding in a divided society: Structural and contextual constraints on the development of critical dialogic discourse in schools. Compare: A Journal of Comparative and International Education, 44, 53-76.

Ross, A. (2007). Multiple identities and education for active citizenship. British Journal of Educational Studies, 55(3), 286-303.

Schartner, A., \& Cho, Y. (2017). 'Empty signifiers' and 'dreamy ideals': perceptions of the 'international university' among higher education students and staff at a British university. Higher Education, 74(3), 455-472.

Vidovich, L. (2004). Towards internationalizing the curriculum in a context of globalization: Comparing policy processes in two settings. Compare: a Journal of Comparative and International Education, 34, 443-461.

Wang, S., Wang, W., Zhuang, Y., \& Fei, X. (2015). An ontology evolution method based on folksonomy. Journal of Applied Research and Technology, 13(2), 177-187.

Yemini, M. (2018). Global/local nexus: between global citizenship and nationalism in a super-diverse London school. International Studies in Sociology of Education, 27(2-3), 271-287. 
Miri Yemini, Heela Goren \& Claire Maxwell (2018) Global Citizenship Education in the Era Of Mobility, Conflict and Globalisation, British Journal of Educational Studies, 66:4, 423-432.

Yemini, M., \& Furstenburg, S. (2018). Students' perceptions of global citizenship at a local and an international school in Israel. Cambridge Journal of Education, (ahead of print).

Yemini, M., Tibbitts, F., \& Goren., H. (2018). Trends and caveats: Review of literature on global citizenship education in teacher training. Teaching and Teacher Education, (ahead of print). 